\title{
Edaravone protects the retina against ischemia/reperfusion-induced oxidative injury through the PI3K/Akt/Nrf2 pathway
}

\author{
YI-PIN XU, FANG HAN and JIAN TAN \\ Department of Plastic Surgery, Shanghai Tenth People's Hospital, Tongji University, Shanghai 200072, P.R. China
}

Received August 10, 2016; Accepted May 15, 2017

DOI: $10.3892 / \mathrm{mmr} .2017 .7739$

\begin{abstract}
Retinal ischemia/reperfusion (I/R) injury can occur as a result of a number of ocular diseases or ischemic events in the brain, leading to possible vision loss if not treated properly. The overproduction of reactive oxygen species is important in the process of I/R injury. Edaravone, a free radical scavenger, has been demonstrated to have a neuroprotective effect in cerebral ischemia; however, its effect against retinal I/R injury remains to be fully elucidated. Therefore, the present study investigated the effects of edaravone on the oxidative parameters, retinal inflammation and apoptosis induced by $\mathrm{I} / \mathrm{R}$ injury, and treated photoreceptor-derived $661 \mathrm{~W}$ cells with hydrogen peroxide $\left(\mathrm{H}_{2} \mathrm{O}_{2}\right)$ and edaravone to examine the underlying mechanism. For the in vivo study, oxidative parameters (malondialdehyde, DNA fragmentation, total antioxidant status, superoxide dismutase and glutathione) in the retina, retinal thickness, and apoptotic index in the ganglionic cell layer and inner nuclear layer were measured. For the in vitro study, the effects of edaravone or nuclear factor erythroid-2-related factor 2 (Nrf2) small interfering RNA or phosphatidylinositol 3-kinase (PI3K)/Akt inhibitors on cell viability, membrane integrity, levels of phosphorylated-Akt, Akt and nuclear $\mathrm{Nrf} 2$ of $\mathrm{H}_{2} \mathrm{O}_{2}$-treated $661 \mathrm{~W}$ cells were examined. The results demonstrated that edaravone inhibited the oxidative injury in the retina induced by the retinal I/R procedure and increased retinal inflammation, and apoptosis. The results of the in vitro experiments demonstrated that edaravone effectively protected the viability and the membrane integrity of the $\mathrm{H}_{2} \mathrm{O}_{2}$-treated $661 \mathrm{~W}$ cells via the phosphatidylinositol 3-kinase (PI3K)/Akt/Nrf2pathway. These results indicated the potential protective effect of edaravone against retinal I/R injury and provided a novel explanation for the protective effects of edaravone.
\end{abstract}

Correspondence to: Professor Jian Tan, Department of Plastic Surgery, Shanghai Tenth People's Hospital, Tongji University, 301 Yanchang Road, Shanghai 200072, P.R. China

E-mail: tanjian200072@163.com

Key words: retina, ischemia/reperfusion injury, edaravone, oxidative injury, phosphatidylinositol 3-kinase/Akt/nuclear factor erythroid-2-related factor 2 pathway

\section{Introduction}

As an important sensory organ, the retina converts photon energy into electrical impulses and transmits them to the brain. As a result, the retina has a high metabolic function and requires a continuous blood supply, which is provided by the choriocapillaris and the central retinal artery (1). However, the high rate of blood flow makes the retina susceptible to ischemia/reperfusion (I/R) injury. Retinal I/R injury can result from a number of ocular diseases, including retinal vascular occlusion, anterior optic neuropathy, diabetic retinopathy and glaucoma (2-5). In addition, ischemic events in the central nervous system can also cause irreversible loss of neurons present in surrounding areas, including the retina. Retinal I/R injury usually results in retinal ganglion cell death due to their vulnerability to ischemia $(6,7)$. The time interval for retinal ischemia to cause irreversible damage is $\sim 1 \mathrm{~h}$ (8). It is widely accepted that $I / R$ injury is caused by the increased generation of reactive oxygen species (ROS) during the process of I/R, including superoxide $\left(\mathrm{O}_{2}^{-}\right)$, hydrogen peroxide $\left(\mathrm{H}_{2} \mathrm{O}_{2}\right)$ and hydroxyl radicals $(\mathrm{OH})(9,10)$. Excessive ROS can react with DNA, lipids and proteins, leading to DNA breakage, lipid peroxidation and protein inactivation.

Edaravone has been shown to be neuroprotective in cerebral ischemia and has been approved for the treatment of cerebral infarction (11). Previous investigations have found that edaravone can eliminate $\mathrm{OH}$ and other ROS, including $\mathrm{O}_{2}{ }^{-}$and nitric oxide radicals, and inhibit $\mathrm{H}_{2} \mathrm{O}_{2}$-induced lipid peroxidation $(12,13)$. Edaravone can also activate anti-oxidative enzymes, including superoxide dismutase (SOD), catalase and guaiacol peroxidase (14). These findings suggest that edaravone may be effective for the treatment of retinal $I / R$ injury. However, few investigations have examined the potential of edaravone in the prevention or treatment of retinal $I / R$ injury, with the exception of a previous study by Song et al, which indicated that edaravone protected the retina from I/R injury in rats through reducing oxidative stress and inhibiting apoptosis of retinal neurons (15). However, the mechanism remains to be elucidated, and a detailed understanding of the molecular events following $\mathrm{I} / \mathrm{R}$ induced retinal damage can facilitate the development of relevant treatments.

In the present study, retinal I/R injury was induced in rats and the effects of edaravone on oxidative parameters, including malondialdehyde (MDA), DNA fragmentation, total 
antioxidant status (TAS), SOD and glutathione (GSH) in the retina were investigated. Secondly, the retinal thickness and apoptotic index (AI) in the ganglion cell layer (GCL) and inner nuclear layer (INL) were measured to examine the protective effect of edaravone against I/R injury. To investigate the underlying mechanism, photoreceptor-derived $661 \mathrm{~W}$ cells were treated with $1 \mathrm{mmol} / 1 \mathrm{H}_{2} \mathrm{O}_{2}$ to induce oxidative injury and with different concentrations of edaravone. The cell viability and levels of cellular lactate dehydrogenase (LDH) were examined, and involvement of the phosphatidylinositol 3-kinase (PI3K)/Akt kinase/nuclear factor erythroid-2-related factor 2 (Nrf2) pathway was investigated.

\section{Materials and methods}

Animals and drugs. Male Sprague-Dawley rats (8-12 weeks old, each weighing $220 \pm 50 \mathrm{~g}$ ) were used in the present study. The animals were housed in the Hospital Animal Center of the Shanghai Tenth People's Hospital in polycarbonate cages at $25^{\circ} \mathrm{C}$ on a $12-\mathrm{h}$ light/dark cycle, and were allowed free access to food and tap water. Ethical approval was obtained from the ethics committee of Tongji University (Shanghai, China) and performed in accordance with the National Institute of Health Guide for the Care and Use of Laboratory Animals (16). The rats were randomly divided into five groups: Control (rats received no treatment); Sham (rats received a sham retinal I/R surgery); I/R (rats received retinal I/R surgery and normal saline injection); I/R+edaravone (rats received a retinal I/R surgery and edaravone injection); Edaravone (rats received edaravone injection only). The edaravone injection was purchased from Nanjing Xiansheng Pharmaceutical Co., Ltd. (Nanjing, China). The edaravone and the normal saline were administered intraperitoneally at a dose of $6 \mathrm{mg} / \mathrm{kg}$ body weight.

Retinal I/R injury procedure. The procedure used to induce retinal I/R injury was as previously described (17). Initially, the rats were anesthetized with an intraperitoneal injection of $1 \%$ pentobarbital sodium $(10 \mathrm{mg} / \mathrm{kg})$. Following corneal analgesia with $0.4 \%$ oxybuprocainehydrochloride and dilation of the pupil with $0.5 \%$ tropicamide and $0.5 \%$ phenylephrine, a 30-gauge needle was cannulated with the anterior chamber of the right eye. The other end of the needle was connected to a saline reservoir. Secondly, the pressure of the reservoir was increased to $150 \mathrm{~cm}$ above the eye, with the intraocular pressure maintained at $110 \mathrm{mmHg}$ to produce retinal ischemia, which was confirmed by corneal edema. After $1 \mathrm{~h}$, the pressure of the reservoir was decreased to the rat eye level and the infusion needle was removed from the anterior chamber to resume retinal blood supply. To prevent post-surgery infection, erythromycin eye ointment was applied following surgery.

Oxidative parameter measurement. Following completion of retinal reperfusion, the retinas of the enucleated eyes were removed for the measurement of oxidative parameters, MDA, DNA fragmentation, TAS, SOD and GSH. Following tissue homogenization and centrifugation $(5,000 \mathrm{x}$ g, $5 \mathrm{~min}$, $4^{\circ} \mathrm{C}$ ), the supernatant was collected and detected using an MDA detection kit (Beyotime Institute of Biotechnology, Haimen, China) using a method similar to that described by Ohkawa et al (18). The MDA level was determined using athiobarbituric acid fluorometric method at $553 \mathrm{~nm}$ with excitation at $515 \mathrm{~nm}$, using 1,1,3,3-tetramethoxypropane as the standard. DNA fragmentation was assessed by quantification of cytosolic oligonucleosome-bound DNA using a Cell Death Detection ELISA Plus kit (Roche Diagnostics GmbH, Mannheim, Germany). The level of TAS in the supernatant was determined using an automated measurement method with a commercially available kit developed by Rel Assay Diagnostics (Gaziantep, Turkey). The results are expressed as mmol Trolox equivalent per mg tissue protein. SOD activity was measured using an SOD colorimetry assay kit from Beyotime Institute of Biotechnology using a nitrobluetetrazolium reduction assay method. A single unit of SOD was defined as the quantity exhbiting $50 \%$ inhibition. GSH was measured using 5,5'-bis-dithionitrobenzoic acid reagent (19) and expressed as $\mathrm{mg} / \mathrm{mg}$ tissue protein.

Measurements of retinal thickness and AI in ganglion cell layer (GCL) and inner nuclear layer (INL). For the measurements of retinal thickness, the retinas were fixed in formalin and embedded in paraffin. Thick sections $(5-\mu \mathrm{m})$ of the retinas were cut to include the full length from superior to inferior along the vertical meridian and mounted on microscope slides, followed by staining with hematoxylin and eosin. Retinal thickness was measured in each section within 0.5-1 mm superior and inferior to the optic disc. Three measurements from each section were obtained to determine the average value.

For the measurements of AI in the GCL and INL, the sections were first incubated with proteinase $\mathrm{K}$ and hydrogen peroxide at $37^{\circ} \mathrm{C}$ for $5 \mathrm{~min}$. Subsequently, the sections were stained using an apoptosis detection kit (EMD Millipore, Billerica, MA, USA) to detect double-strand breaks in genomic DNA with diaminobenzidine. The sections were analyzed in a blinded-manner in 10 microscopic fields from images captured using an Olympus digital microscope (Olympus, Tokyo, Japan). The average numbers of TUNEL-positive cells were counted in each image.

Cell culture and treatment. The $661 \mathrm{~W}$ mouse photoreceptor cells (Shanghai Aulu Biological Technology Co., Ltd., Shanghai, China) were cultured in DMEM with $10 \%$ fetal bovine serum (FBS; Beyotime Institute of Biotechnology Co., Ltd.) in a sterile humidified environment at $37^{\circ} \mathrm{C}$ in $95 \%$ $\mathrm{O}_{2}$ and $5 \% \mathrm{CO}_{2}$ according to the manufacturer's protocol. The cells were seeded into 6 -well plates $12 \mathrm{~h}$ prior to treatment, and then divided into six groups: Control, $\mathrm{H}_{2} \mathrm{O}_{2}$ group (treated with $1 \mathrm{mmol} \mathrm{H}_{2} \mathrm{O}_{2}$ for $2 \mathrm{~h}$ ), $\mathrm{H}_{2} \mathrm{O}_{2}+25 \mu \mathrm{M}$ Eda group (treated with $1 \mathrm{mmol} \mathrm{H}_{2} \mathrm{O}_{2}$ and $25 \mu \mathrm{M}$ edaravone for $2 \mathrm{~h}$ ), $\mathrm{H}_{2} \mathrm{O}_{2}+50 \mu \mathrm{M}$ Eda group (treated with $1 \mathrm{mmol}_{2} \mathrm{O}_{2}$ and $50 \mu \mathrm{M}$ edaravone for $2 \mathrm{~h}$ ), $\mathrm{H}_{2} \mathrm{O}_{2}+100 \mu \mathrm{M}$ Eda group (treated with $1 \mathrm{mmol} \mathrm{H}_{2} \mathrm{O}_{2}$ and $100 \mu \mathrm{M}$ edaravone for $2 \mathrm{~h}$ ) and $100 \mu \mathrm{M}$ Eda group (treated with $100 \mu \mathrm{M}$ edaravone for $2 \mathrm{~h}$ ). Edaravone was purchased from Yuanye Biotech (Shanghai, China). Different doses of edaravone $(25,50$ and $100 \mu \mathrm{M})$ were added to the culture $30 \mathrm{~min}$ prior to $\mathrm{H}_{2} \mathrm{O}_{2}$ treatment. In the second phase of the cell experiment, the $661 \mathrm{~W}$ cells were divided into five groups: $\mathrm{H}_{2} \mathrm{O}_{2}$ group (treated with $1 \mathrm{mmol} \mathrm{H}_{2} \mathrm{O}_{2}$ for $2 \mathrm{~h}$ ), $\mathrm{H}_{2} \mathrm{O}_{2}+\mathrm{Eda}+\mathrm{LY} 294002$ group (treated with $1 \mathrm{mmol} \mathrm{H} \mathrm{O}_{2}, 50 \mu \mathrm{M}$ edaravone and $20 \mu \mathrm{M}$ LY294002 for $2 \mathrm{~h}$ ), $\mathrm{H}_{2} \mathrm{O}_{2}+\mathrm{Eda}+\mathrm{Nrf} 2$ small interfering (si)RNA group 
(treated with $1 \mathrm{mmol} \mathrm{H}_{2} \mathrm{O}_{2}, 50 \mu \mathrm{M}$ edaravone and $\mathrm{Nrf} 2$ siRNA for $2 \mathrm{~h}$ ), $\mathrm{H}_{2} \mathrm{O}_{2}+\mathrm{Eda}+$ triciribine group (treated with $1 \mathrm{mmol}$ $\mathrm{H}_{2} \mathrm{O}_{2}, 100 \mu \mathrm{M}$ edaravone and $5 \mu \mathrm{M}$ triciribine for $2 \mathrm{~h}$ ). In the third phase of the cell experiments, the $661 \mathrm{~W}$ cells were divided into six groups (control group and the same groups as in the second phase of the cell experiments). LY249002, purchased from Sigma-Aldrich; Merck Millipore (Darmstadt, Germany) was added to the medium to reach a final concentration of $20 \mu \mathrm{M}$. Nrf2-siRNA was purchased from Qiagen, Inc. (Valencia, CA, USA), including HP-validated siRNA and all stars Neg. siRNA AF488. The following sense and antisense sequences were used for Nrf2-siRNA forwards, 5'-GUAAGA AGCCAGAUGUUA AdUdU-3' and reverse, 3'-dUdUCAUUCUUCGGUCUACAATT-5'. The $661 \mathrm{~W}$ cells were transfected with Nrf2-siRNA for $72 \mathrm{~h}$ using HiPerFect transfection reagent according to the manufacturer's protocol (Qiagen, Inc.). Triciribine, purchased from Sigma-Aldrich; Merck Millipore, was added to the medium to reach a final concentration of $5 \mu \mathrm{M}$.

Cell viability and LDH leakage assay. Cell viability was determined using an MTT assay kit (Beyotime Institute of Biotechnology) similar to the method described by Bai et al (20). The cells were cultured in a 96 -well plate $\left(0.2 \times 10^{6}\right.$ cells $\left./ \mathrm{ml}\right)$ for treatment. Following treatment of the cells, $100 \mu \mathrm{l}$ MTT solution $(1 \mathrm{mg} / \mathrm{ml}$ in medium without serum and phenol red) was added to each well and the plates were incubated at $37^{\circ} \mathrm{C}$ for $3 \mathrm{~h}$. Following incubation, the medium on top was removed and isopropanol was added to each well to dissolve the formazan crystals. Finally, the absorbance values were measured at $570 \mathrm{~nm}$ with an EIX-800 Micro elisa reader (BioTek Instruments, Inc., Winooski, VT, USA). Cell survival rates were determined as percentages of that of normal cells. The LDH leakage assay kit (CytoTox $96^{\circledR}$ non-radioactive cytotoxicity assay) was a product of Promega Corporation (Madison, WI, USA). The $661 \mathrm{~W}$ cells were seeded into 96 -well plates $12 \mathrm{~h}$ prior to treatment. Following treatment of the cells, $20 \mu \mathrm{l}$ of the medium was transferred to a new 96-well plate to measure LDH activity, according to the manufacturer's protocol, as described by Chang et al (21).

Western blot analysis. Following treatment of the $661 \mathrm{~W}$ cells, the cells were harvested and then re-suspended in lysis buffer (Cell lysis buffer for Western and immunoprecipitation; Beyotime Institute of Biotechnology). The samples were then centrifuged at $12,000 \mathrm{xg}$ for $10 \mathrm{~min}$ at $4^{\circ} \mathrm{C}$ and the supernatants were collected. The total protein levels were measured using a bicinchoninic assay (Roche Diagnostics $\mathrm{GmbH}$ ). The protein $(25 \mu \mathrm{g})$ was separated by $10 \%$ SDS-PAGE and transferred onto polyvinylidenedifluoride membranes (EMD Millipore). The membranes were blocked in 5\% nonfat milk and then incubated with primary rabbit polyclonal antibodies against Akt (cat. no. sc-5298; 1:1,500), phosphorylated-Akt (p-Akt; cat. no. sc-293125; 1:2,000) and Nrf2 (cat. no. sc-365949; 1:2,000), which were bought from Santa Cruz Biotechnology, Inc., Santa Cruz, CA, USA), in $5 \mathrm{ml}$ of $5 \%$ bovine serum albumin wash buffer (Beyotime Institute of Biotechnology) at $4^{\circ} \mathrm{C}$ overnight. The membranes were then washed and incubated with secondary anti-rabbit immunoglobulin G (1:2,000; cat. no. sc-2030; Santa Cruz Biotechnology, Inc.) in 5\% milk wash solution for $1 \mathrm{~h}$ at $25^{\circ} \mathrm{C}$. Digitized images of protein bands were quantitated using AlphaEaseFC ${ }^{\mathrm{TM}}$ software (version 4.0.0; Witec, Littau, Switzerland). $\beta$-actin was used as an internal control.

Statistical analysis. The data are expressed as the mean \pm standard deviation of triplicate experiments, with at least eight separate experiments performed for each condition $(n \geq 8)$. Differences among means were assessed using a one-way analysis of variance followed by the Student-Newman-Keuls post hoc test. $\mathrm{P}<0.05$ was considered to indicate a statistically significant difference. All statistical analyses were performed using SPSS 17.0 (SPSS, Inc., Chicago, IL, USA).

\section{Results}

Oxidative parameters are increased by $I / R$ and inhibited by edaravone. The changes in oxidative parameters (MDA, DNA fragmentation, TAS, SOD and GSH) are exhibited in Table I. No significant alterations in these parameters were found in the Sham rats. The rats exposed to retinal I/R exhibited significant increases in MDA and DNA fragmentation, and significant decreases in TAS, SOD and GSH, compared with the control and sham group $(\mathrm{P}<0.05)$. However, these changes in the parameters in the $\mathrm{I} / \mathrm{R}$ group were all significantly inhibited in the I/R+edaravone group: MDA and DNA fragmentation were decreased; and levels of TAS, SOD and GSH were increased $(\mathrm{P}<0.05)$. Compared with the control and sham groups, no significant changes in these parameters were observed in the edaravone group, with the exception of increased TAS $(\mathrm{P}<0.05)$.

Edaravone inhibits the changes in retinal thickness, and AI in the GCL and INL induced by I/R. The changes of retinal thickness and AI in the GCL and INL following treatment of edaravone are shown in Table II. No significant changes in these parameters were observed in the Sham rats $(\mathrm{P}>0.05)$. The rats exposed to retinal I/R exhibited a significant increase in retinal thickness, and increased AI in the GCL and INL, compared with those in the Control and Sham groups $(\mathrm{P}<0.05)$. These parameters in the $\mathrm{I} / \mathrm{R}+$ edaravone group were significantly lower, compared with those in the $\mathrm{I} / \mathrm{R}$ group $(\mathrm{P}<0.05)$. Compared with the Control and Sham group, no significant changes were observed in these parameters in the edaravone group $(\mathrm{P}>0.05)$.

Edaravone protects cell viability and membrane integrity of $\mathrm{H}_{2} \mathrm{O}_{2}$-treated $661 \mathrm{~W}$ cells. The results of the cell viability analysis showed that: i) $\mathrm{H}_{2} \mathrm{O}_{2}$ treatment significantly decreased the viability of the $661 \mathrm{~W}$ cells $(\mathrm{P}<0.05)$; ii) $25 \mu \mathrm{M}$ edaravone had no significant effect on the cell viability of $\mathrm{H}_{2} \mathrm{O}_{2}$-treated $661 \mathrm{~W}$ cells, however, 50 and $100 \mu \mathrm{M}$ edaravone increased cell viability $(\mathrm{P}<0.05)$; iii) edaravone alone did not alter cell viability (Fig. 1A). The analysis of LDH leakage demonstrated similar results: i) $\mathrm{H}_{2} \mathrm{O}_{2}$ treatment significantly increased $\mathrm{LDH}$ leakage $(\mathrm{P}<0.05)$; ii) $25 \mu \mathrm{M}$ edaravone did not significantly affect LDH leakage, however, 50 and $100 \mu \mathrm{M}$ edaravone significantly decreased leakage $(\mathrm{P}<0.05)$; ii) edaravone alone did not affect LDH leakage (Fig. 1B). 
Table I. Changes in oxidative parameters following treatment with Eda.

\begin{tabular}{|c|c|c|c|c|c|}
\hline Parameter & Control & Sham & $\mathrm{I} / \mathrm{R}$ & $\mathrm{I} / \mathrm{R}+\mathrm{Eda}$ & Eda \\
\hline MDA ( $\mu \mathrm{mol} / \mathrm{mg}$ protein) & $9.02 \pm 1.12$ & $8.59 \pm 1.24$ & $16.69 \pm 2.33^{\mathrm{a}}$ & $11.12 \pm 1.05^{\mathrm{b}}$ & $9.12 \pm 1.26$ \\
\hline DNA fragmentation (U/mg protein) & $2.14 \pm 0.36$ & $2.07 \pm 0.25$ & $3.69 \pm 0.27^{\mathrm{a}}$ & $2.26 \pm 0.29^{\mathrm{b}}$ & $2.05 \pm 0.21$ \\
\hline TAS (mmol trolox equiv./mg protein) & $0.52 \pm 0.04$ & $0.41 \pm 0.05$ & $0.36 \pm 0.07^{\mathrm{a}}$ & $0.67 \pm 0.05^{\mathrm{b}}$ & $0.77 \pm 0.06$ \\
\hline SOD (\% inhibition/mg protein) & $33.29 \pm 2.54$ & $31.14 \pm 2.63$ & $21.18 \pm 2.29^{\mathrm{a}}$ & $28.64 \pm 2.04^{\mathrm{b}}$ & $35.26 \pm 3.22$ \\
\hline GSH $(\mu \mathrm{g} / \mathrm{mg}$ protein $)$ & $3.15 \pm 0.26$ & $3.08 \pm 0.22$ & $2.36 \pm 0.17^{\mathrm{a}}$ & $2.89 \pm 0.18^{\mathrm{b}}$ & $3.19 \pm 0.31$ \\
\hline
\end{tabular}

Values are expressed as the mean \pm standard error of the mean. ${ }^{\mathrm{P}}<0.05$, compared with the Sham group; ${ }^{\mathrm{b}} \mathrm{P}<0.05$, compared with the $\mathrm{I} / \mathrm{R}+\mathrm{Eda}$ group. Eda, edaravone; I/R, ischemia/reperfusion; MDA, malondialdehyde; TAS, total antioxidant status; SOD, superoxide dismutase; GSH, glutathione.

Table II. Changes in retinal thickness and AI in the GCL and INL following treatment with EDA.

\begin{tabular}{|c|c|c|c|c|c|}
\hline Parameter & Control & Sham & $\mathrm{I} / \mathrm{R}$ & $\mathrm{I} / \mathrm{R}+\mathrm{Eda}$ & Eda \\
\hline Retinal thickness $(\mu \mathrm{m})$ & $159.5 \pm 14.2$ & $167.6 \pm 16.3$ & $266.1 \pm 18.4^{\mathrm{a}}$ & $184.6 \pm 20.7^{b}$ & $162.5 \pm 13.2$ \\
\hline $\mathrm{AI}$ in GCL $(\%)$ & $15.23 \pm 1.64$ & $14.46 \pm 1.25$ & $27.42 \pm 1.58^{\mathrm{a}}$ & $14.56 \pm 2.02^{\mathrm{b}}$ & $17.63 \pm 2.11$ \\
\hline $\mathrm{AI}$ in INL (\%) & $6.37 \pm 0.59$ & $6.32 \pm 0.63$ & $18.71 \pm 0.91^{\mathrm{a}}$ & $7.45 \pm 1.05^{\mathrm{b}}$ & $6.58 \pm 0.77$ \\
\hline
\end{tabular}

Values are expressed as the mean \pm standard error of the mean. ${ }^{\mathrm{a}} \mathrm{P}<0.05$, compared with the Sham group; ${ }^{\mathrm{b}} \mathrm{P}<0.05$, compared with the $\mathrm{I} / \mathrm{R}$ group. Eda, edaravone; I/R, ischemia/reperfusion; AI, apoptotic index; GCL, ganglion cell layer; INL, inner nuclear layer.
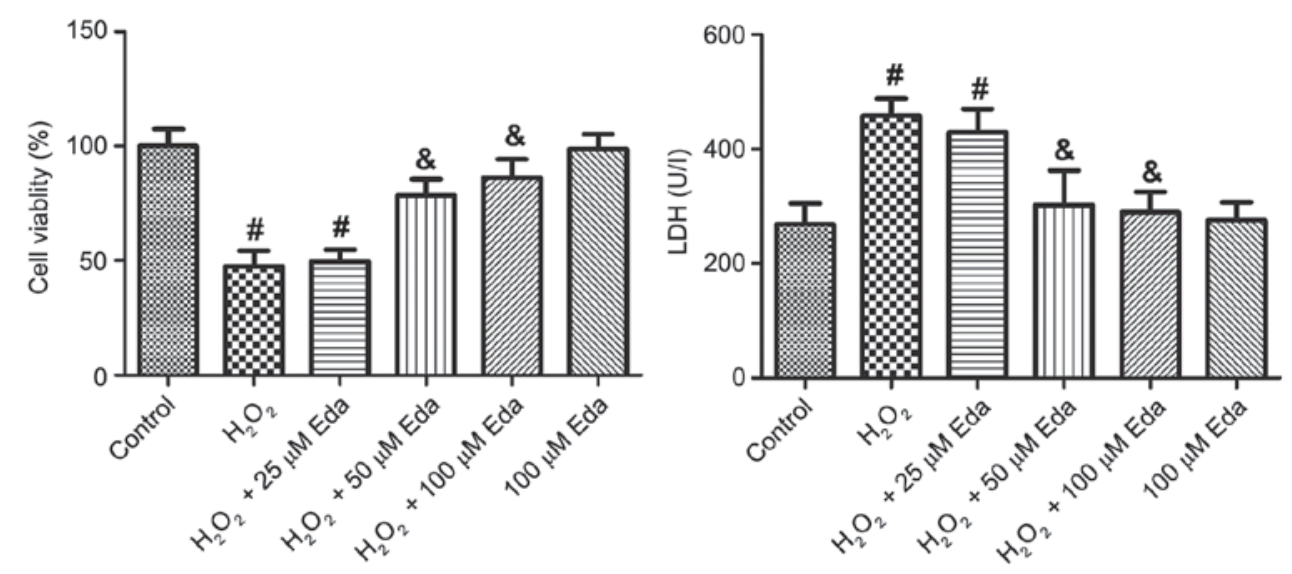

Figure 1. Effects of Eda on the viability and membrane integrity of $\mathrm{H}_{2} \mathrm{O}_{2}$-treated $661 \mathrm{~W}$ cells. ${ }^{*} \mathrm{P}<0.05$, compared with the Control group; ${ }^{k} \mathrm{P}<0.05$, compared with the $\mathrm{H}_{2} \mathrm{O}_{2}$ group. Eda, edaravone; $\mathrm{H}_{2} \mathrm{O}_{2}$, hydrogen peroxide.

Expression levels of $p$-Akt, Akt and nuclear Nrf2 in $661 \mathrm{~W}$ cells are increased by edaravone. The expression levels of p-Akt, Akt and nuclear Nrf2 in cells were altered by oxidative stress and edaravone, as shown in Fig. 2. It was demonstrated that, following exposure of the $661 \mathrm{~W}$ cells to $\mathrm{H}_{2} \mathrm{O}_{2}$ for $2 \mathrm{~h}$, no significant changes were observed in the protein expression levels of p-Akt, Akt or nuclear Nrf2 (P>0.05). In the presence of $25 \mu \mathrm{M}$ edaravone, the expression of $\mathrm{p}$-Akt, Akt and nuclear Nrf2 remained unchanged, however, treatment with 50 and $100 \mu \mathrm{M}$ edaravone led to significant increases in $\mathrm{p}$-Akt/Akt and nuclear Nrf2 $(\mathrm{P}<0.05)$. Pretreatment with $100 \mu \mathrm{M}$ edaravone alone also significantly increased the expression levels of p-Akt/Akt and nuclear Nrf2 in cells, compared with those in the Control $(\mathrm{P}<0.05)$.
Expression levels of p-Akt, Akt and Nrf2 in $661 \mathrm{~W}$ cells are inhibited by Nrf2 siRNA or PI3K/Akt inhibitors. The expression of p-Akt, Akt (Fig. 3A) and Nrf2 (Fig. 3B) in cells were altered by Nrf2 siRNA and the PI3K/Akt inhibitors. As shown in Fig. 3A, treatment with Nrf2 siRNA had no significant effect on the $\mathrm{p}$-Akt/Akt ratio $(\mathrm{P}>0.05)$, however, the $\mathrm{PI} 3 \mathrm{~K}$ inhibitor (LY294002) and Akt inhibitor (triciribine) significantly decreased the p-Akt/Akt ratio $(\mathrm{P}<0.05)$. For Nrf2 (Fig. 3B), the Nrf2 siRNA and the PI3K/Akt inhibitor significantly decreased its expression $(\mathrm{P}<0.05)$.

Nrf2 siRNA or PI3K/Akt inhibitors counter the protective effect of edaravone on cell viability and membrane integrity of $661 \mathrm{~W}$ cells. The viabilities of $661 \mathrm{~W}$ cells in the presence of PI3K/Akt 

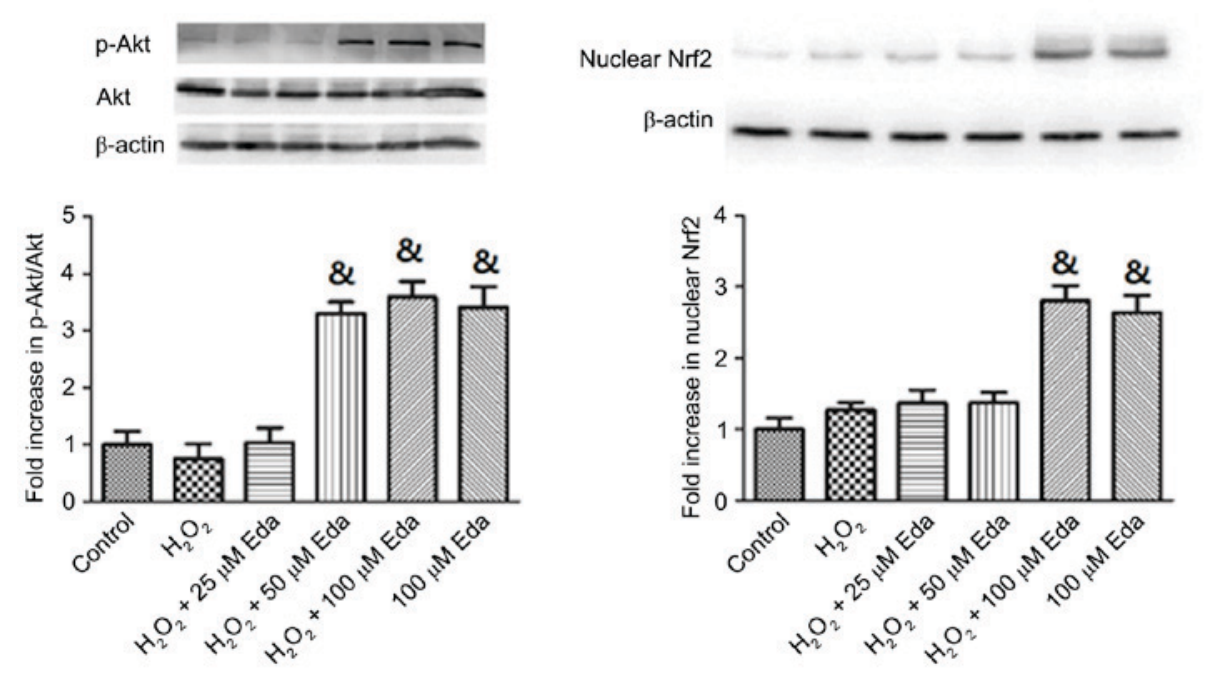

Figure 2. Changes in the expression of p-Akt, Akt and Nrf2 in $661 \mathrm{~W}$ cells by oxidative stress and/or Eda. ${ }^{\#} \mathrm{P}<0.05$, compared with the Control group; ${ }^{\circledR} \mathrm{P}<0.05$, compared with the $\mathrm{H}_{2} \mathrm{O}_{2}$ group. Eda, edaravone; Nrf2, nuclear factor erythroid-2-related factor 2; p-, phosphorylated; $\mathrm{H}_{2} \mathrm{O}_{2}$, hydrogen peroxide.
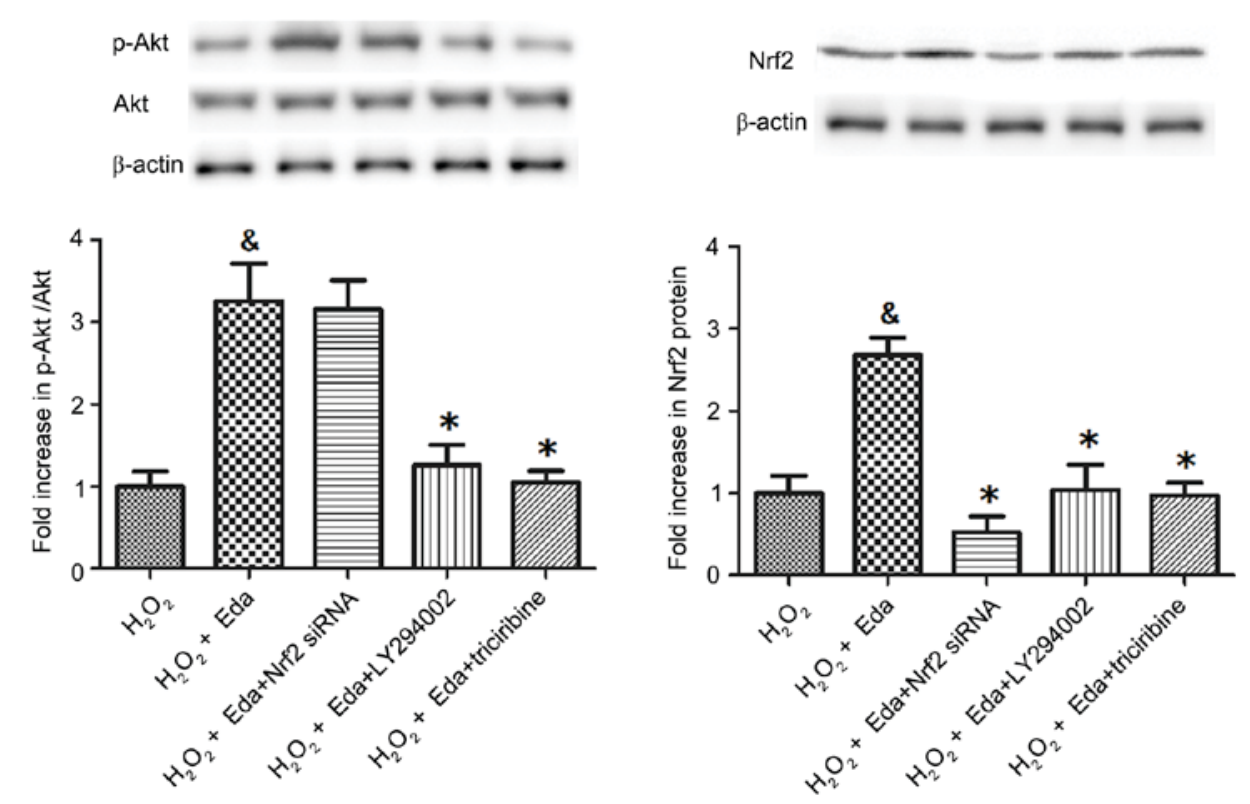

Figure 3. Changes in the expression of p-Akt, Akt and Nrf2 in $661 \mathrm{~W}$ cells by Nrf2 siRNA or PI3K/Akt inhibitors. The concentration of Eda used was $50 \mu \mathrm{M}$. ${ }^{\&} \mathrm{P}<0.05$, compared with the $\mathrm{H}_{2} \mathrm{O}_{2}$ group; " $\mathrm{P}<0.05$, compared with the $\mathrm{H}_{2} \mathrm{O}_{2}+$ Eda group. Eda, edaravone; Nrf2, nuclear factor erythroid-2-related factor 2; p-, phosphorylated; $\mathrm{H}_{2} \mathrm{O}_{2}$, hydrogen peroxide; siRNA, small interfering RNA; PI3K, phosphatidylinositol 3-kinase.

inhibitors or Nrf2 siRNA are exhibited in Fig. 4A. Treatment of cells with Nrf2 siRNA, PI3K inhibitor (LY294002) or Akt inhibitor (triciribine) all eliminated the effect of edaravone on cell viability $(\mathrm{P}<0.05)$. The membrane integrities of $661 \mathrm{~W}$ cells in the presence of Nrf2 siRNA or PI3K/Akt inhibitors are shown in Fig. 4B. Treatment with Nrf2 siRNA, LY294002 and triciribine all eliminated the effect of edaravone on LDH leakage $(\mathrm{P}<0.05)$.

\section{Discussion}

Retinal I/R injury is associated with various conditions, which can culminate in blindness if effective treatment is not provided (22). The retina consists of neurons, vasculature and glia, and each of these compartments can be affected in retinal
$\mathrm{I} / \mathrm{R}$ injury (23-25). The exact mechanism of cell death due to retinal I/R injury remains to be fully elucidated, however, it has been previously demonstrated that, in conditions of oxidative stress, retinal ganglion cells are damaged as a result of increased intracellular ROS and calcium influx (26). In the process of I/R, ROS are extensively generated in the early stage of reperfusion and can cause serious damage to various organs, including the brain and heart $(27,28)$. It has also been demonstrated in multiple studies that the oxidative stress induced by ROS is key in the pathophysiological mechanisms involved in retinal I/R injury (29,30). As demonstrated in the results of the present study, the rats exposed to retinal I/R exhibited a significant increase in MDA and DNA fragmentation, suggesting that ROS caused the peroxidation of cellular lipid in addition to DNA oxidative damage. It also significantly 

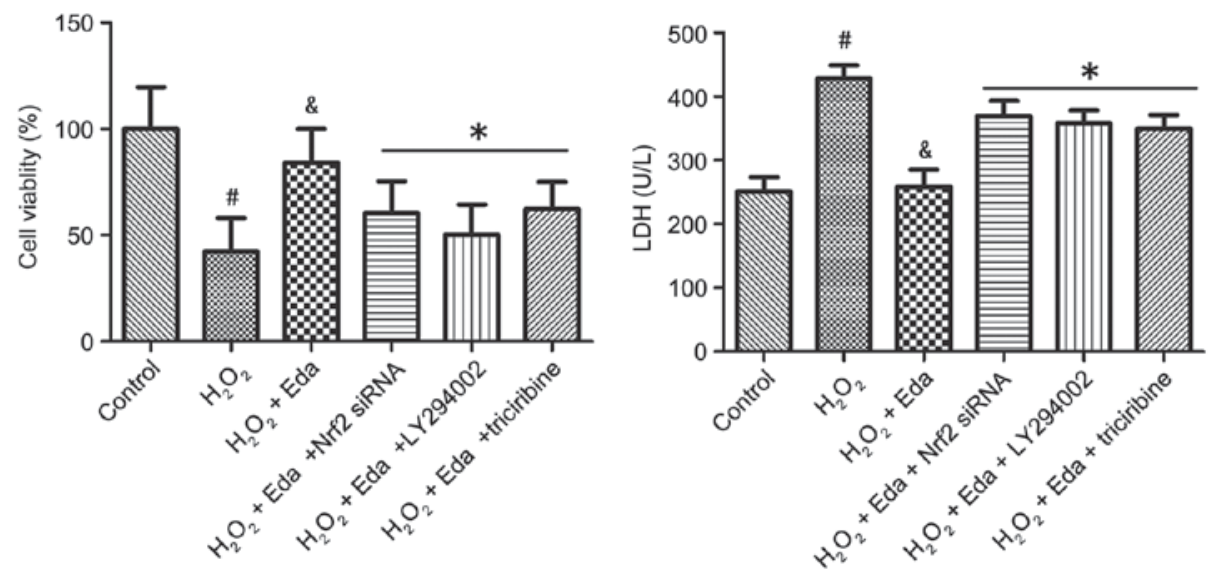

Figure 4. Changes in cell viability and membrane integrity of $661 \mathrm{~W}$ cells in the presence of Nrf2 siRNA or PI3K/Akt inhibitors. The concentration of Eda used was $50 \mu \mathrm{M}$. " $\mathrm{P}<0.05$, compared with the Control group; ${ }^{\&} \mathrm{P}<0.05$, compared with the $\mathrm{H}_{2} \mathrm{O}_{2}$ group; ${ }^{*} \mathrm{P}<0.05$, compared with the $\mathrm{H}_{2} \mathrm{O}_{2}+$ Eda group. Eda, edaravone; Nrf2, nuclear factor erythroid-2-related factor 2; $\mathrm{H}_{2} \mathrm{O}_{2}$, hydrogen peroxide; siRNA, small interfering RNA; PI3K, phosphatidylinositol 3-kinase.

decreased the levels of TAS, SOD and GSH, indicating that the balance of oxidative/anti-oxidative in the retina was disturbed by I/R procedure. The production and accumulation of excessive ROS is considered to be important in the mechanism of I/R injury. ROS are the major free radicals in human body, including $\mathrm{O}_{2}^{-}, \mathrm{OH}$ and $\mathrm{H}_{2} \mathrm{O}_{2}$. The nicotinamide adenine dinucleotide phosphate oxidase system, in conjunction with mitochondria, is a major site of ROS generation under $\mathrm{H}_{2} \mathrm{O}_{2}(31)$.

The overproduction of ROS can induce several inflammatory mediators, including interleukin $1-\beta$ and tumor necrosis factor- $\alpha$, and apoptosis in the retina (32-34). As a result, inflammation and cell apoptosis are considered to be major causes of the pathological changes following I/R injury. As exhibited in Table II, the rats exposed to retinal I/R procedure exhibited significant increases in retinal thickness and apoptotic indices in the GCL and INL. The increase of retinal thickness indicated that the I/R injury caused retinal inflammation, whereas the increase of AI in the GCL and INL demonstrated cell apoptosis was induced by $\mathrm{I} / \mathrm{R}$.

Edaravone, a novel free radical scavenger, has been approved for the treatment of ischemic stroke in China and Japan. It is widely accepted that it produces neuroprotective effects by scavenging free radicals, and inhibiting lipid peroxidation and oxidative damage to cells (13). In the animal experiments performed in the present study, it was found that edaravone effectively attenuated the disruption of oxidative/anti-oxidative balance induced by retinal I/R injury. The oxidative parameters following $I / R$ injury were all significantly inhibited by edaravone: MDA and DNA fragmentation were decreased; TAS, SOD and GSH were increased. Furthermore, edaravone significantly decreased retinal thickness and AI in the GCL and INL, indicating its protection against the retinal inflammation and cell apoptosis induced by I/R. These results were consistent with those in a study by Song et al (15). In this previous study, rats were injected with edaravone at $30 \mathrm{~min}$ prior to ischemia, following which retinal ischemia was induced by elevating intraocular pressure to $110 \mathrm{mmHg}$ for $60 \mathrm{~min}$ and then treated with edaravone twice daily for 1 or 5 days post-I/R. An electroretinogram was recorded 5 days following reperfusion. It was concluded that edaravone lowered levels of MDA, increased SOD activity, and attenuated I/R-induced apoptosis of retinal neurons and suppressed I/R-induced reduction in a- and b-wave amplitudes of ERG. However, the molecular events following I/R-induced retinal damage were not examined. Understanding the underlying mechanisms may facilitate the development of relevant treatments.

To further examine the underlying mechanism of the protective effect of edaravone, the present study treated $661 \mathrm{~W}$ cells, a mouse photoreceptor cell line, with $\mathrm{H}_{2} \mathrm{O}_{2}$ to produce oxidative stress, and examine the effect of edaravone on cell viability and injury. The results showed that edaravone dose-dependently enhanced cell viability, which was decreased by $\mathrm{H}_{2} \mathrm{O}_{2}$ treatment; it also dose-dependently protected cell integrity, which was impaired by $\mathrm{H}_{2} \mathrm{O}_{2}$, demonstrated by LDH leakage. Subsequently, the present study determined the effects of $\mathrm{H}_{2} \mathrm{O}_{2}$ and edaravone on the activation of Akt and expression of Nrf2. The results of the western blot analysis showed no significant changes in the protein expression levels of p-Akt, Akt or Nrf2 in the presence of $\mathrm{H}_{2} \mathrm{O}_{2}$, however, edaravone significantly increased p-Akt/Akt and Nrf2. The p-Akt/Akt ratio was not affected by treatment with Nrf2 siRNA, but was significantly decreased by the PI3K inhibitor (LY294002) or Akt inhibitor (triciribine). By contrast, the expression of Nrf2 was inhibited by Nrf2 siRNA and thePI3K/Akt inhibitors.

It has been revealed that the PI3K-mediated generation of 3'-phosphorylated phosphoinositide leads to the recruitment of Akt to the cell membrane, where it is phosphorylated by kinases, including phosphoinositide-dependent kinase-1, leading to the activation of Akt (35). Nrf2 is an important transcription factor in the coordinated expression of stress-inducible genes. Several studies have shown that Nrf2 can regulate the expression of phase-II detoxification and antioxidant response element, including glutathione synthase, hemeoxygenase (HO)-1 and catalase, under oxidative stress, and can be activated by the PI3K/Akt pathway. For example, PI3K/Akt can facilitate the release of Nrf2 from the Keap1-Nrf2 complex, and enables it to translocate into the nucleus and induce phase II defense enzymes (36). A study by Hua et al (37) demonstrated that edaravone 
significantly induced the translocation of Nrf2 and HO-1 to the nucleus, and markedly increased components of the cellular antioxidant defense system, including GSH, SOD and HO-1, consistent with the present study. It is possible that the rearrangement of actin microfilaments and the increase of cellular $\mathrm{Ca}^{2+}$ are involved in the regulation of $\mathrm{Nrf} 2$ via the PI3K/Akt pathway (38).

In conclusion, the present study revealed that edaravone inhibited oxidative injury in the retina induced by retinal $\mathrm{I} / \mathrm{R}$, and reduced the increases of retinal inflammation and apoptosis. In vitro experiments demonstrated that edaravone effectively protected cell viability and the membrane integrity of the $\mathrm{H}_{2} \mathrm{O}_{2}$-treated $661 \mathrm{~W}$ cells via the $\mathrm{PI} 3 \mathrm{~K} / \mathrm{Akt} / \mathrm{Nrf} 2$ pathway. These results indicate the potential protective effect of edaravone against retinal I/R injury and provide a novel explanation for the protective effects of edaravone.

\section{References}

1. Kaur C, Foulds WS and Ling EA: Blood-retinal barrier in hypoxic ischaemic conditions: Basic concepts, clinical features and management. Prog Retin Eye Res 27: 622-647, 2008.

2. Archer DB: Tributary vein obstruction: Pathogenesis and treatment of sequelae. Doc Ophthalmol 40: 339-360, 1976.

3. Hayreh SS: Ischemic optic neuropathy. Int Ophthalmol 1: 9-18, 1978.

4. Verma D: Pathogenesis of diabetic retinopathy-the missing link? Med Hypotheses 41: 205-210, 1993.

5. Nickells RW: Retinal ganglion cell death in glaucoma: The how, the why, and the maybe. J Glaucoma 5: 345-356, 1996.

6. Hayreh SS, Zimmerman MB, Kimura A and Sanon A: Central retinal artery occlusion. Retinal survival time. Exp Eye Res 78: 723-736, 2004

7. Mukaida Y, Machida S, Masuda T and Tazawa Y: Correlation of retinal function with retinal histopathology following ischemia-reperfusion in rat eyes. Curr Eye Res 28: 381-389, 2004.

8. Aydemir O, Celebi S, Yilmaz T, Yekeler H and Kükner AS: Protective effects of vitamin E forms (alpha-tocopherol, gamma-tocopherol and d-alpha-tocopherol polyethylene glycol 1000 succinate) on retinal edema during ischemia-reperfusion injury in the guinea pig retina. Int Ophthalmol 25: 283-289, 2004.

9. Pace PW, Yao LJ, Wilson JX, Possmayer F, Veldhuizen RA and Lewis JF: The effects of hyperoxia exposure on lung function and pulmonary surfactant in a rat model of acute lung injury. Exp Lung Res 35: 380-398, 2009.

10. Reddy NM, Kleeberger SR, Kensler TW, Yamamoto M, Hassoun PM and Reddy SP: Disruption of Nrf2 impairs the resolution of hyperoxia-induced acute lung injury and inflammation in mice. J Immunol 182: 7264-7271, 2009.

11. Watanabe T, Tanaka M, Watanabe K, Takamatsu Y and Tobe A: Research and development of the free radical scavenger edaravone as a neuroprotectant. Yakugaku Zasshi 124: 99-111, 2004.

12. Kaur C and Ling EA: Antioxidants and neuroprotection in the adult and developing central nervous system. Curr Med Chem 15: 3068-3080, 2008.

13. Yoshida H, Yanai H, Namiki Y, Fukatsu-Sasaki K, Furutani N and Tada N: Neuroprotective effects of edaravone: A novel free radical scavenger in cerebrovascular injury. CNS Drug Rev 12: 9-20, 2006

14. Liu S, Li R, Ni X, Cai Z, Zhang R, Sun X, Quock RM and Xu W: Perfluorocarbon-facilitated CNS oxygen toxicity in rats: Reversal by edaravone. Brain Res 1471: 56-65, 2012.

15. Song Y, Gong YY, Xie ZG, Li CH, Gu Q and Wu XW: Edaravone (MCI-186), a free radical scavenger, attenuates retinal ischemia/reperfusion injury in rats. Acta Pharmacol Sin 29 823-828, 2008

16. Institute of Laboratory Animal Resources, Commission on Life Sciences, National Research Council, Guide for the Care and Use of Laboratory Animals. National Academy Press, Washington, DC, 1996.
17. Tong N, Zhang Z, Gong Y, Yin L and Wu X: Diosmin protects rat retina from ischemia/reperfusion injury. J Ocul Pharmacol Ther 28: 459-466, 2012

18. Ohkawa H, Ohishi W and Yagi K: Determination of lipid peroxidation by MDA. Anal Biochem 95: 351-358, 1979.

19. Pathak R, Suke SG, Ahmed T, Ahmed RS, Tripathi AK, Guleria K, Sharma CS, Makhijani SD and Banerjee BD: Organochlorine pesticide residue levels and oxidative stress in preterm delivery cases. Hum Exp Toxicol 29: 351-358, 2010.

20. Bai L, Pang WJ, Yang YJ and Yang GS: Modulation of Sirt1 by resveratrol and nicotinamide alters proliferation and differentiation of pig preadipocytes. Mol Cell Biochem 307: 129-140, 2008.

21. Chang Y, Yang ST, Liu JH, Dong E, Wang Y, Cao A, Liu Y and Wang H: In vitro toxicity evaluation of graphene oxide on A549 cells. Toxicol Lett 200: 201-210, 2011.

22. Osborne NN, Casson RJ, Wood JP, Chidlow G, Graham M and Melena J: Retinal ischemia: Mechanisms of damage and potential therapeutic strategies. Prog Retin Eye Res 23: 91-147, 2004

23. Zheng L, Gong B, Hatala DA and Kern TS: Retinal ischemia and reperfusion causes capillary degeneration: Similarities to diabetes. Invest Ophthalmol Vis Sci 48: 361-367, 2007.

24. Fernandez DC, Bordone MP, Chianelli MS and Rosenstein RE: Retinal neuroprotection against ischemia-reperfusion damage induced by postconditioning. Invest Ophthalmol Vis Sci 50: 3922-3930, 2009

25. Li C, Wang L, Huang $\mathrm{K}$ and Zheng L: Endoplasmic reticulum stress in retinal vascular degeneration: Protective role of resveratrol. Invest Ophthalmol Vis Sci 53: 3241-3249, 2012.

26. Maher $P$ and Hanneken A: Flavonoids protect retinal ganglion cells from oxidative stress-induced death. Invest Ophthalmol Vis Sci 46: 4796-4803, 2005.

27. Peters O, Back T, Lindauer U, Busch C, Megow D, Dreier J and Dirnagl U: Increased formation of reactive oxygen species after permanent and reversible middle cerebral artery occlusion in the rat. J Cereb Blood Flow Metab 18: 196-205, 1998.

28. Kevin LG, Camara AK, Riess ML, Novalija E and Stowe DF: Ischemic preconditioning alters real-time measure of $\mathrm{O} 2$ radicals in intact hearts with ischemia and reperfusion. Am J Physiol Heart Circ Physiol 284: H566-H574, 2003.

29. Chen YQ, Pan WH, Liu JH, Chen MM, Liu CM, Yeh MY, Tsai SK, Young MS, Zhang XM and Chao HM: The effects and underlying mechanisms of S-allyl 1-cysteine treatment of the retina after ischemia/reperfusion. J Ocul Pharmacol Ther 28: 110-117, 2012.

30. Valko M, Leibfritz D, Moncol J, Cronin MT, Mazur M and Telser J: Free radicals and antioxidants in normal physiological functions and human disease. Int J Biochem Cell Biol 39: 44-84, 2007.

31. Parinandi NL, Kleinberg MA, Usatyuk PV, Cummings RJ, Pennathur A, Cardounel AJ, Zweier JL, Garcia JG and Natarajan V: Hyperoxia-induced NAD $(\mathrm{P}) \mathrm{H}$ oxidase activation and regulation by MAP kinases in human lung endothelial cells. Am J Physiol Lung Cell Mol Physiol 284: L26-L38, 2003.

32. Schwartz M: Neuroprotection as a treatment for glaucoma: Pharmacological and immunological approaches. Eur J Ophthalmol 13 (Suppl 3): S27-S31, 2003.

33. Clutton $\mathrm{S}$ : The importance of oxidative stress in apoptosis. $\mathrm{Br}$ Med Bull 53: 662-668, 1997.

34. Meldrum DR, Dinarello CA, Cleveland JC Jr, Cain BS, Shames BD, Meng X and Harken AH: Hydrogen peroxide induces tumor necrosis factor alpha-mediated cardiac injury by a P38 mitogen-activated protein kinase-dependent mechanism. Surgery 124: 291-297, 1998.

35. Toker A and Cantley LC: Signalling through the lipid products of phosphoinositide-3-OH kinase. Nature 387: 673-676, 1997.

36. Ryu MJ, Kang KA, Piao MJ, Kim KC, Zheng J, Yao CW, Cha JW, Chung HS, Kim SC, Jung E, et al: 7,8-Dihydroxyflavone protects human keratinocytes against oxidative stress-induced cell damage via the ERK and PI3K/Akt-mediated Nrf2/HO-1 signaling pathways. Int J Mol Med 33: 964-970, 2014.

37. Hua K, Sheng X, Li TT, Wang LN, Zhang YH, Huang ZJ and $\mathrm{Ji} \mathrm{H}$ : The edaravone and 3-n-butylphthalide ring-opening derivative $10 \mathrm{~b}$ effectively attenuates cerebral ischemia injury in rats. Acta Pharmacol Sin 36: 917-927, 2015.

38. Kang KW, Lee SJ and Kim SG: Molecular mechanism of nrf2 activation by oxidative stress. Antioxid Redox Signal 7: 1664-1673, 2005 